\title{
Referaat
}

\section{Scholarship of teaching en carrière: zijn publicaties de (enige) juiste maat?}

$\mathrm{Al}$ in 1990 bracht Boyer ${ }^{1}$ een hoop beroering teweeg met zijn verhandeling over 'scholarship', een woord waarbij het Nederlandse 'wetenschappelijkheid' het dichtst in de buurt lijkt te komen. Vooral de introductie van het 'scholarship of teaching' (als synoniem wordt ook 'educational scholarship' gebruikt) naast scholarships van onderzoek ('discovery'; 'research'), integratie ('integration') en toepassing ('application') riep veel reacties op vanuit het werkveld, waarin de frustraties over de onderwaardering van onderwijs sterk doorklonken. Glassick pakte dit onderwerp op en formuleerde als criteria voor alle vormen van scholarship: heldere doelstelling, goede voorbereiding, juiste methoden, relevante resultaten, effectieve presentatie en reflectie. ${ }^{2}$ Deze criteria blijken vrij eenvoudig toepasbaar te zijn op het onderwijs. 'Scholarship of teaching' onderscheidt zich van het geven van goed, activerend onderwijs dat gebaseerd is op actuele onderwijskundige inzichten, op grond van de volgende elementen: het werk is: a) publiek toegankelijk, b) open voor beoordeling en kritiek volgens geaccepteerde maatstaven en c) reproduceerbaar en vormt een basis om op voort te bouwen. ${ }^{4-5}$ Deze elementen bieden tevens een aanzet om tot een kwalitatieve en kwantitatieve beoordeling te komen die gebruikt kan worden bij een onderwijscarrièrebeleid, anders dan op basis van onderzoek van onderwijs, dat gewogen kan worden volgens de criteria voor wetenschappelijk onderzoek. Voor het waarderen van het 'scholarship of teaching' zullen naast (onderzoeks)publicaties dan ook andere onderwijskundige producten zoals (onderdelen van) ontwikkelde curricula, (digitaal) onderwijsmateriaal, syllabi en goed gedocumenteerde, nieuwe toets-, evaluatie- of onderwijsmethoden meegewogen moeten worden, evenals blijken van erkenning uit de beroepsgroep zoals verkregen onderwijsprijzen en functies in (inter)nationale onderwijsorganisaties. ${ }^{5-9}$ Voor een effectief onderwijscarrièrebeleid is het bovendien noodzakelijk dat onderwijs binnen de instellingscultuur serieus genomen wordt en herkenbaar aanwezig is in de infrastructuur. ${ }^{3-4} 7$ Dit zou o.a. kunnen blijken uit helder gedefinieerde onderwijscarrièrelijnen en betrokkenheid van collega's uit het onderwijsveld bij benoemingen en promoties. ${ }^{38}$ Opmerkelijk is dat, zelfs waar aan deze voorwaarden wordt voldaan, het toch langer blijkt te duren carrière te maken binnen het onderwijs dan binnen het onderzoek. ${ }^{6}$ Tenslotte, van een andere kant benaderd: binnen de geneeskunde is het heel gebruikelijk expertise binnen een deelgebied van de patiëntenzorg ('scholarship of application') te belonen, bijvoorbeeld met een leerstoel al dan niet ingesteld door een patiëntenvereniging. Ook hierbij wegen veelal andere factoren mee dan alleen wetenschappelijke productie.

Samenvattend en concluderend pleit ik ervoor om voor een carrière in het medisch onderwijs, naast wetenschappelijke productie, heldere criteria te formuleren voor het meten en waarderen van bijdragen aan de ontwikkeling en bevordering van goed onderwijs. Als deze criteria zijn vastgelegd kunnen geïnteresseerden in een 
carrière binnen het medisch onderwijs zich hierop richten, instellingen hen faciliteren en zo hun beste 'educational scholars' behouden.

\section{Ineke Molenaar, Centrum voor Docent- professionalisering, Faculteit der Medische Wetenschappen, Universitair Medisch Centrum Groningen}

\section{Literatuur}

1. Boyer EL. Scholarship reconsidered. Princeton New Jersey, The Carnegie Foundation for the advancement of Teaching: 1990

2. GlassickCE. Boyer's expanded definitions of scholarship, the standards for assessing scholarship, and the elusiveness of the scholarship of teaching. Acad Med 2000:75:877-880.

3. Fincher RM, Simpson DE, Mennin SP, Rosenfeld GC, RothmanA, McGrew MC et al. Scholarship in teaching: an imperative for the 21 st century. Acad Med 2000:75:887-894.
4. Hutchings $P$ and ShulmanLS. The scholarship of teaching: new elaborations, new developments. Change 1999:31:10-15.

5. Collins J. Teacher or educational scholar? They aren't the same. J Am Coll Radiol 2004:1:135-139.

6. Sherertz EF. Criteria of the "educators' pyramid" fulfilled by medical school faculty promoted on a teaching pathway. Acad Med 2000:75:954-956.

7. Simpson D, Fincher RM, Hafler JP, Irby DM, Richards BF, Rosenfeld GC et al. Advancing educators and education by defining the components and evidence associated with educational scholarship. Med Educ 2007:41:1002-1009.

8. Sachdeva AK, Cohen R, Dayton MT, Hebert JC, Jamieson C, Neumayer LA et al. A new model for recognizing and rewarding the educational accomplishments of surgery faculty. Acad Med 1999: 74:1278-1287.

9. Atasoylu AA, Wright SM, Beasley BW, Cofrancesco J, Jr, Macpherson DS, Partridge T et al. Promotion criteria for clinician-educators. J Gen Intern Med 2003:18:711-716. 